\title{
DISTRIBUCIÓN URBANA DE LA MINORÍA JUDÍA EN GALICIA: LA JUDERÍA ${ }^{1}$
}

\author{
$M^{a}$ GLORIA DE ANTONIO RUBIO \\ Instituto de Estudios Gallegos «Padre Sarmiento». CSIC-Xunta de Galicia
}

\begin{abstract}
Resumen
Las causas que originaron el nacimiento de las juderías o barrios propios de los judíos hay que buscarlas, por un lado, en la tendencia natural de toda minoría a agruparse para mantener su propia identidad y, por otro, en las medidas de segregación adoptadas por la sociedad cristiana. Galicia no es ajena a esta tendencia, documentándose desde muy temprano la existencia de barrios propios de los judíos (Allariz, año 1289), aunque la mayoría de los documentos hagan referencia a juderías de finales del siglo XV (Ribadavia, Ourense y A Coruña) y a su ubicación en el recinto de la ciudad o villa correspondiente.
\end{abstract}

\section{Palabras Clave}

Edad Media, Galicia, judíos, juderías.

\begin{abstract}
The reasons for the beginning of the «juderias» (jewish quarters) are to be found, firstly, in the natural trend of every minority to gather so as to safeguard their own identity; secondly, in the segregation policies taken by the christian society. Galicia is not foreign to this tendency. Since early times (Allariz, A.D. 1289) the existence of jewish quarters is well documented, although most documents refer to jewish quarters in late XV Century (Ribadavia, Ourense and A Coruña) and to their location in their respective area of the town or village.
\end{abstract}

\section{Key Words}

Midlle Age, Galicia, Jews, Jewish quarter.

${ }^{1}$ Este artículo ha sido desarrollado en el Instituto de Estudios Gallegos «Padre Sarmiento», dentro del proyecto Diccionario biográfico de la Galicia de los Tratámara, dirigido por Dr. D. Eduardo Pardo de Guevara y Valdés y financiado por la Fundación Pedro Barrié de la Maza. 


\section{CONCEPTO DE JUDERÍA}

A lo largo de la historia, los judíos han mantenido siempre una tendencia a agruparse en sectores urbanos propios, apartados del resto de la población, allí donde constituyeron un sector minoritario en el conjunto de la sociedad. Esta propensión, común a todo grupo socio-religioso minoritario, tiene por finalidad garantizar la pervivencia del colectivo así como propiciar el mantenimiento de los imprescindibles lazos de protección y ayuda mutuas. Pese a que no fue extraño que algunos judíos viviesen en casas distribuidas por todo el recinto urbano, se aprecia una cierta tendencia a agruparse en una calle o en un barrio propio. Nacieron así barrios para la población hebrea, más o menos aislados del recinto urbano, que se conocen con el nombre de «judería» ${ }^{2}$.

Así pues, la judería fue el barrio o zona habitada por los judíos mientras que la «aljama» fue la «institución jurídica» que acogió a los $\operatorname{mismos}^{3}$ ya que, durante su permanencia en el suelo de la Península Ibérica, se organizaron en forma de comunidades locales autónomas, semejantes a los municipios, que fueron llamadas «aljamas» por los juristas medievales ${ }^{4}$.

Las juderías solían situarse en los sectores urbanos considerados como seguros $\mathrm{y}$, por este motivo, fue habitual encontrar juderías localizadas o bien dentro del recinto del castillo o fortaleza, o bien próximas al perímetro amurallado.

Según el tamaño de la comunidad, el barrio judío podía ocupar una o varias calles. En ciudades como Toledo, Ávila, Sevilla o Zaragoza el barrio judío se extendía considerablemente. Las calles y callejuelas que lo conformaban eran, por regla general, estrechas y sinuosas. Este plano urbanístico, posiblemente heredado de la tradición islámica, obedecía a una voluntad de aprovechar mejor el escaso espacio físico disponible, así como facilitar la defensa en el caso de un asalto. En juderías de cierta importancia las distintas callejuelas solían agruparse en torno a una calle principal, conocida como «Calle Mayor de la judería», y a una «Plaza de la judería» o «Plaza de la sinagoga», en la que, normalmente, se ubicaba la sinagoga mayor de la aljama. Para su mayor protección, la judería solía rodearse con una muralla, en la que se abrían una o más puertas: Una, que ponía en comunicación al barrio judío con el resto de la población, y otras que abrían la judería hacia el exterior del recinto urbano 5 .

\footnotetext{
${ }^{2}$ CANTERA MONTENEGRO, Enrique, Aspectos de la vida cotidiana de los judios en la Españ medieval, Madrid 1998, 145.

${ }^{3}$ ROMANO, David, «Aljama frente a judería, call y sus sinónimos», Sefarad 34 (1979), 347-54.

${ }^{4}$ SUÁREZ FERNÁNDEZ, Luis, Judios españoles en la Edad Media, Madrid 1980, 29.

${ }^{5}$ CANTERA MONTENEGRO, Enrique, Aspectos de la vida, 147.
} 


\section{ORIGEN DE LAS JUDERÍAS}

El origen de las juderías hay que buscarlo, además de en el agrupamiento voluntario de toda minoría étnica, en la superioridad manifestada por la sociedad cristiana sobre la judía y en la legislación y otras medidas encaminadas a impedir el trato de judíos con cristianos y que pretendían una auténtica segregación social y espacial.

La sociedad cristiana, con los instrumentos de poder que tenía en su mano (corona, iglesia, estado), partía del supuesto de la superioridad de su fe sobre cualquier religión, incluido el judaísmo. La tolerancia o la protección de las minorías religiosas se ejerció siempre desde la base de esta superioridad. Por este motivo, cuando las tendencias antijudías cobraron fuerza, especialmente desde finales del siglo XIII, el deterioro de la convivencia condujo a un aislamiento progresivo de la población judía, lo que puede considerarse como un resultado deseado recíprocamente por ambas comunidades ${ }^{6}$. Sirvan como ejemplo las ordenanzas de Sevilla de 1252 que obligaban a los judíos a arrodillarse al cruzarse en la calle con una procesión del Santísimo o, al menos, a no estar presentes ${ }^{7}$, o el siguiente texto de Las Partidas: «Otrosi defendemos que el dia del viernes santo ningund judio non sea osado de salir fuera de su casa, nin de su barrio: mas esten y encerrados, fasta el sabado en la mañana» ${ }^{8}$.

Para conseguir la segregación social se establecieron normas de convivencia a través de disposiciones legales que tuvieron reflejo en todos los ámbitos legislativos y que pretendían, además de la exclusión de las labores administrativas que tuvieran jurisdicción sobre cristianos, -«ningun judío nunca ouiese jamás lugar horrado, nin oficio público con que pudiesse apremiar a ningun christiano en ninguna manera» ${ }^{9}-$, regular la vida diaria. Por ejemplo:

«... Otrosi defendemos que ningund christiano, nin christiana non conbide a ningun judío, nin judía nin, reciba, otrosí conbite dellos para comer, nin beuer en vno, nin beuan del vino que es fecho por mano de ellos. $\mathrm{E}$ aun mandamos que ningund judío

${ }^{6}$ RUIZ GÓMEZ, Francisco, «Juderías y aljamas en el mundo rural de la Castilla medieval», Actas do congreso Internacional, Xudeos e Conversos na Historia, Santiago de Compostela 1994, p. $111-52$

${ }^{7}$ MONSALVO ANTÓN, José María, Teoría y evolución y evolución de un conflicto social. El antisemitismo en la Corona de Castilla en la Baja Edad Media, Madrid 1985, 141-42.

${ }^{8}$ Partida VII ${ }^{\mathrm{a}}$, tit. XIV, ley II.

${ }^{9}$ Partida VII ${ }^{\mathrm{a}}$, tit. XXIV, ley III. 
non sea osado de bañarse en baño en vno con los christianos. E otrosí defendemos que ningund christiano no reciba melezinamiento, nin purga que sea fecha por mano de judio. Pero bien puede recibir la por consejo de algund sabidor tan solamente que sea fecha por mano de christiano que conozca, e entienda las cosas que son en ella ... $\rangle^{10}$.

Prohibiciones que se repetirán a lo largo de todo el siglo XV tanto en la legislación real como eclesiástica.

La segregación espacial, es decir las medidas encaminadas a conseguir una separación en barrios determinados, aparecen antes del siglo XV en la legislación eclesiástica, -la primera vez en el Concilio de Palencia del año 1388 cuando se obliga a los judíos a vivir cercados, aunque se les permite salir durante el día a lugares públicos a vender o a trabajar en sus talleres ${ }^{11}$, y en los cuadernos de Cortes. En estos últimos la necesidad de separación de los judíos en barrios o calles apartadas se menciona únicamente en 1351, en las Cortes de Valladolid ${ }^{12}$.

Sin embargo, a lo largo del siglo XV se consolida la idea de la necesidad de apartar físicamente a los judíos a zonas reservadas. Esta idea se recoge en la legislación real, -Pragmática de doña Catalina en 1412-, en la legislación eclesiástica, -Bula de Benedicto XIII de 1415-y en los cuadernos de Cortes, -Cortes de Toledo de 1480 -.

En la Pragmática promulgada por la reina de Castilla doña Catalina en 1412, se contienen disposiciones muy severas para con los judíos, entre ellas, la que obligaba al apartamiento de la población hebrea en barrios especiales, convenientemente aislados de los sectores urbanos habitados por los cristianos:

«... $1^{\circ}$ Primeramente que de aquí adelante todos los judíos e moros e moras de los mis Regnos e Sennoríos sean é vivan apartados de los christianos, en un logar aparte de la Çibdad, Villa ú logar, donde fueren veçinos, é que sean çercados de una çerca en derredor .... ${ }^{13}$.

Todo hace suponer que esta disposición no fue llevada a la práctica con rigor y que, en la mayor parte de los casos, los judíos continuaron residiendo en los mismos barrios en que lo habían venido haciendo hasta entonces. Pero desde este

\footnotetext{
${ }^{10}$ Partida VII ${ }^{\mathrm{a}}$, tit. XXIV, ley VIII ${ }^{\mathrm{a}}$.

${ }^{11}$ MONSALVO ANTÓN, José María, Teoría y evolución, 157.

${ }^{12}$ MONSALVO ANTÓN, José María, Teoría y evolución, 171.

${ }^{13}$ AMADOR DE LOS RÍOS, José, Historia social, política y religiosa de los judios de España y Portugal, Valencia 1994, tomo II, 619.
} 
momento, y a lo largo del siglo XV, la Pragmática de doña Catalina servirá como modelo para algunos proyectos de apartamiento de los judíos promovidos por las autoridades concejiles.

En la Bula de Benedicto XIII de 1415 se exhorta a los príncipes y señores para que los judíos sean encerrados en sus zonas reservadas y no puedan salir de allí:

«... exortamos á los Príncipes fieles y á otros Señores temporales, en nombre de Cristo, para que en sus ciudades, villas y lugares, donde moran judíos, fijen ciertos límites, fuera de los cuales no les sea permitido habitar. Á los judíos, que tuvieren sus casas, de contínua habitación fuera de los límites señalados, castíguenlos con la pena ya designada: los fieles que osáren vender, alquilar, ó ceder en otro cualquier modo su casa, si fueren singulares personas, tendrán la pena de excomunión: si formaren en cambio colegio ú otra universidad, reconózcanse desde luego incursos en la sentencia de entredicho .... $\rangle^{14}$.

En el año 1480, en las Cortes de Toledo, entre otras medidas, los Reyes Católicos ordenaron que todos los judíos del reino, aunque morasen en tierras de behetrías, abadengos o de órdenes, dejasen sus viviendas y fueran a residir en lugares apartados de los cristianos y de los conversos ${ }^{15}$ :

«... ordenamos e mandamos que todos los judios e moros de todas e quales quier cibdades e uillas e lugares ddestos nuestros reynos, quier sean delo realengo o sennorios e behertias e ordenes e abadengos, tengan sus jederias e morerias destintas e apartadas sobre si, e no moren a vueltas con los christianos, ni ayan barrios con ellos, lo qual mandamos que se faga e cumpla dentro de dos annos primeros siguientes, contados desde el dia que fueren publicadas e pregonadas estas nuestras leyes en la nuestra corte .... $\rangle^{16}$.

Es decir, la sociedad cristiana, desde todos los ámbitos legislativos, intentó, con desigual éxito, la segregación social y espacial de los judíos, utilizando para ello todos los mecanismos de los que disponía y que le permitían mantener su superioridad.

\footnotetext{
${ }^{14}$ AMADOR DE LOS RÍOS, José, Historia social, politica, tomo II, 640-1.

${ }^{15}$ MONSALVO ANTÓN, José María, Teoría y evolución, 171.

${ }^{16}$ Cortes de los Antiguos reinos de León y Castilla, tomo IV, 149.
} 


\section{JUDERÍAS EN GALICIA}

Las juderías gallegas, siguiendo el modelo general de ubicación de las juderías en la Corona de Castilla, se localizaron bien dentro del recinto amurallado bien en una zona segura de la ciudad.

En cuanto al modelo de distribución de la población, se pueden identificar comunidades judías gallegas concentradas en torno a una calle única, (Ribadavia); comunidades viviendo dispersas por toda la ciudad pero con tendencia a agruparse libremente en una calle principal, (Ourense); o comunidades de las que se conoce la existencia de una judería pero de las que, en cambio, se desconoce si sus habitantes se agrupaban en torno a una calle principal o vivían dispersos por la ciudad, tal es el caso de los judíos de A Coruña o Allariz. Todas estas juderías presentan como característica común el estar documentadas en el siglo XV, excepto la judería de Allariz cuya existencia se recoge en el año 1289 en la denominada «Carta de avenencia» y que se analizará en primer lugar.

\section{Judería de Allariz}

La «carta de avenencia», cuyo original no se conserva en la actualidad pero de la que existen varias transcripciones completas publicadas por Amador de los Ríos ${ }^{17}$ y Benito Fernández Alonso ${ }^{18}$ y una parcial publicada por Puga Brau ${ }^{19}$ que difiere de la anteriores sobre todo en el protocolo inicial, pretendía ser la solución a los problemas que enfrentaban a la sociedad cristiana y a la sociedad judía.

En el origen del conflicto se encontraban las interferencias judías en las ceremonias religiosas cristianas y viceversa. Para arbitrar una solución se reunieron las autoridades civiles y religiosas alaricanas con el representante de los judíos o Judío Mayor y los acuerdos a los que llegaron ambas partes quedaron reflejados en dicha carta.

Entre las medidas adoptadas se encuentra el apartamiento de los judíos a un barrio separado, lo que supuso una segregación espacial completa, puesto que, por un lado, se prohibió a los judíos vivir fuera de la judería y salir de ella incluso para comerciar: "Que o dito Xudeu Maor nin su jente merquen, troquen nin moren en vivenda fora da Xuderia e non nas outras ruas da vila, do moran os cristians» $\mathrm{y}$, por otro lado, a los cristianos vivir en la judería: «e nengun cristian morará na xuderia». El único espacio cristiano al que los judíos tuvieron acceso fue a las puertas de la

${ }^{17}$ AMADOR DE LOS RÍOS, José, Historia social, política, tomo II, 553-4.

${ }^{18}$ FERNÁNDEZ ALONSO, Benito, Los judios en Orense (siglos XV al XVII), Orense 1904, 24-5.

${ }^{19}$ PUGA BRAU, Xosé, Os xudeos de Allariz, Ourense 1996, 50. 
villa pero exclusivamente para introducir mercancias en la judería: «e entren os xudeos pelas portas da vila para Xuderia os vastimentos, que tiveren por menester».

En el documento no ha quedado ningún rastro que permita señalar el lugar ocupado por la judería, excepto que ésta se encontraba dentro de los muros de la villa. Conclusión que deriva del permiso para «entrar» mercancías por las puertas de la villa para la judería, anteriormente mencionado. El hecho de que no se precise su ubicación permite considerar que la judería ocuparía un lugar conocido por todos y que, probablemente, en esa fecha ya sería un lugar habitado mayoritaria y voluntariamente por judíos.

Existen, sin embargo, ciertos indicios que permiten considerar que la judería se localizaría en la zona alta de la ciudad, en el entorno de San Esteban:

En primer lugar, por la mención al castillo en el párrafo que hace referencia al lugar donde los judíos realizaban sus prácticas religiosas y que parece lógico suponer que sería en la judería o en el lugar habitado mayoritariamente por los judíos: «Nas rogas e festas, que os ditos xudeus fan nos soburvios da vila por vaixo do noso Castelo». Por lo que la judería debía localizarse debajo del castillo, quizá en la ladera del altozano sobre el que éste se ubicaba, en la parte alta de la ciudad. En este caso concreto la palabra «suburbios» estaría haciendo alusión a los arrabales y no a las partes bajas de la villa.

En segundo lugar, en 1487 el rector de la iglesia de San Esteban, ubicada muy próxima al castillo, aforó un terreno cercano a su iglesia para que los judíos ampliasen el cementerio que tenían ya desde hacía tiempo en esos terrenos: «Conven a saber que bai la afueracion para todo sempre, por cuanto teneis vuestras enterramientos ya de luengo tiempo en la dicha eredad $\rangle^{20}$. Fue práctica habitual entre los judíos que el cementerio se situase fuera de la ciudad pero próximo a la puerta de la judería para evitar que los entierros tuvieran que atravesar barrios cristianos $^{21}$. Por lo tanto el cementerio se encontraba también en la parte alta de la ciudad, muy próximo a la iglesia de San Esteban, lo que confirma la idea de que la judería estaría ubicada en esta misma zona.

Como mero indicio se puede apuntar además que, aunque la localización de las propiedades no indica obligatoriamente dónde habita el propietario, en este caso la huerta propiedad del Judío Mayor, que cede al convento de Santa Clara como parte de los acuerdos de la carta de avenencia para ampliar su cementerio, está lógicamente al lado del convento y, por lo tanto, en la parte alta de la villa.

\footnotetext{
${ }^{20}$ Fundación Vicente Risco, sin catalogar.

${ }^{21}$ CANTERA MONTENEGRO, Enrique, Aspectos de la vida, 168.
} 
La documentación no permite conocer que ocurrió después de este acuerdo y si las drásticas medidas adoptadas se llevaron o no a la práctica. Sin embargo, en los últimos años de la década 1480-1490, cuando los recaudadores Mosé y Judá Pérez vivieron en Allariz, no lo hicieron en la zona asignada como judería en 1289 sino en unas casas situadas en el centro de la villa. El motivo podría ser, o bien porque, en su calidad de arrendadores y recaudadores reales, no estuviesen obligados a vivir en ella o bien porque la judería como tal no existiese en estos años. De hecho, cuando en Ourense se ordenó a Mosé Pérez que se apartase a vivir a una zona separada, éste respondió diciendo que era vecino de Allariz desde hacía más de un año y que, por lo tanto, no tenía porqué vivir en la judería, lo que parece indicativo de una menor presión en Allariz que en Ourense.

En cualquier caso, e independientemente de su evolución posterior, la judería de Allariz es la primera judería gallega documentada, ubicada intramuros, por debajo del castillo, en el entorno de la iglesia de San Esteban, en la parte alta de la villa.

\section{Judería de Ribadavia}

La primera noticia sobre los judíos de Ribadavia, que no sobre su judería, se recoge en la crónica de Froissart. Ésta relata el asalto que sufrió la villa en el año 1386 cuando se resistió al avance de las tropas del Duque de Láncaster hacia Castilla, para hacer valer los derechos de su esposa Constanza, hija de Pedro I, a la corona de Castilla.

La compleja y difícil redacción de este apartado de la Crónica ha dado lugar a diversas interpretaciones entre los autores que se han ocupado de precisar el número de judíos que vivían en Ribadavia, en qué zona de la villa habitaban, así como el papel jugado por los judíos en la defensa de la villa ${ }^{22}$.

Con posterioridad a la Crónica de Froissart, los datos sobre la comunidad judía de Ribadavia se reducen a las cantidades abonadas en concepto de los tributos específicos que la población judía debía pagar a la Corona, y a algunas otras escasas noticias sobre algunos de los principales personajes que vivieron en ella. Sin

${ }^{22}$ Ver MERUÉNDANO, Leopoldo, Los judíos de Ribadavia, origen de las cuatro parroquias, Ribadavia 1915, 6-7; OTERO PEDRAYO, Ramón, Guía de Galicia, Vigo 1980, 385; FERNÁNDEZ ALONSO, Benito, Los judios en Orense, 32; RISCO, Vicente, Manual de Historia de Galicia, Vigo 1952, 126; MURGUÍA, Manuel, Galicia, Vigo 1982, 840-1; EIJAN, Samuel, Historia de Ribadavia y sus alrededores, Madrid 1920, 215-23; VICETTO, Benito, Historia de Galicia, Montevideo 1880, tomo V, 238; GONZÁLEZ LÓPEZ, Emilio, Historia de Galicia, La Coruña 1980, 183.

Cuadernos de Estudios Gallegos, Tomo LI, Fascículo 117, Santiago 2004. (Págs. 263 - 279) 
embargo, la documentación de los siglos XVI, XVII y XVIII es lo suficientemente explícita como para permitir la localización de la judería de Ribadavia.

Está compuesta fundamentalmente por contratos de foro o por ventas de casas propiedad del monasterio de Santo Domingo a particulares. Así, entre otros documentos, consta que en 1570 el convento aforó una casa «sita en la calle de la Judairia que fue de Jacome Alonso, a Leonor Rodriguez viuda y a su hija» ${ }^{23}$. En 1577 se renovó el foro anterior y se precisa algo más la ubicación de la «calle de la judairía»: «afora este convento a Leonor Rodriguez, viuda de Juan Portugués, una casa sita en la calle que basa de la plaça mayor para la iglesia de la Madalena ${ }^{24}$. Por lo que se puede afirmar que la «calle de la Judairía» se iniciaba en la Plaza Mayor y terminaba en la iglesia de la Magdalena, información que se confirma en 1678 cuando se compró la casa anterior ${ }^{25}$.

A lo largo del siglo XVII la «calle de la judairía» cambió su nombre por el de "Calle de la Cruz». Este nombre puede hacer referencia al cruce de calles que hay delante de la iglesia de la Magdalena, o bien tener un sentido religioso, pues fue muy frecuente que las calles de la judería recibieran, tras la expulsión de los judíos, nombres relacionados con la religión cristiana: Calle de la Cruz, Calle de la Fe, etc.

Es necesario hacer notar que, aunque en los documentos se hable de una casa "en la calle de la cruz» o en la "cassa de la calle de la cruz de dicha villa», en la parte superior de los mismos siempre se hace constar que se trata de la «calle de la Judairía», lo que permite pensar que sería por este último nombre por el que sería conocida popularmente la calle. Este trazado sigue vigente en la actualidad, y la calle recibe el nombre de Merelles Gaula.

En general, todos los autores que han hecho referencia a la localización de la judería de Ribadavia coinciden en afirmar que ésta se ubicaba en la calle que baja desde la Plaza Mayor hacia la iglesia de la Magdalena. Sin embargo, no todos coinciden en la extensión de esta zona por la villa. Leopoldo Meruéndano y Benito Fernández Alonso afirman que los judíos habitaban entre la Puerta Nueva de Abajo y la de Arriba, con la acera correspondiente de la Magdalena, además de una zona exterior en el barrio de «Los Ferreiros» y de «La Corredoira» ${ }^{26}$. José Luis Lacave sitúa la judería en la actual calle de Merelles Gaula pero, basándose en la

\footnotetext{
${ }^{23}$ AHPOU, Clero, Foros de viñas y casas, caixa 10.070, sin numerar.

${ }^{24}$ AHPOU, Clero, Foros de viñas y casas, caixa 10.070, sin numerar.

${ }^{25}$ AHPOU, Clero, Foros, censos de casas, caixa 10.071, sin numerar.

${ }^{26}$ MERUÉNDANO, Leopoldo, Los judios de Ribadavia, 8-9; FERNÁNDEZ ALONSO, Benito, Los judios en Orense, 32.
} 
obra de Meruéndano, extiende el barrio judío «al espacio que hay entre la Magdalena, la muralla y las ruinas del castillo, es decir, a las calles Puerta Nueva de Arriba, Puerta Nueva de Abajo y Travesía de Puerta Nueva» ${ }^{27}$. Esta afirmación no es compartida por Samuel Eiján quien admite la presencia judía en Ribadavia pero no en un número tan grande como para habitar casi la mitad de la superficie de la villa.

En resumen, y según los datos que ofrece la documentación actual, sólo se puede afirmar que la judería de Ribadavia se localizaba en la "calle de la Judairía», calle que partía de la Plaza Mayor hacia la iglesia de la Magdalena y que en el siglo XVII, aunque quizá ya desde 1492, recibió el nombre de «calle de la Cruz».

\section{Judería de Ourense}

La distribución espacial de los judíos en la ciudad de Ourense es un modelo de judíos dispersos por toda la ciudad, aunque con un predominio claro de una calle, en este caso la Rúa Nova, como lugar elegido libremente para vivir.

Hasta la constitución definitiva de la judería orensana se puede hablar de tres etapas perfectamente definidas: La primera de ellas, hasta el 3 de julio de 1484, -fecha en que ciertos judíos fueron reunidos en la sinagoga para advertirles que en el plazo de tres días se señalaría la zona de la ciudad que se convertiría en judería-, caracterizada por la dispersión de los judíos por la ciudad. La segunda comprendida entre el 3 de Julio de 1484 y el 22 de Mayo de 1487, cuando se dictan las medidas para apartar a los judíos a la judería, concluyendo así la dispersión por diferentes calles de la ciudad. Finalmente una tercera etapa, posterior a 1487, momento en que las autoridades municipales plantean un nuevo traslado de la judería.

\section{Hasta el 3 de Julio de 1484}

Hasta esta fecha los judíos vivieron dispersos por diferentes calles, tales como: la «Plaza del Campo», la «Rúa da Barreira», la «Rúa da Carnicería», la «Rúa da Corredoira», la «Rúa da Pixoteria», la «Rúa da Praça», La «Rúa do Canpo e Tendas», la «Rúa dos Arçedianos», la «Rúa dos Çapateiros» y la «Rúa Nova», -que fue la que contó con un mayor número de judíos y en la que, además, se localizaba la sinagoga, lo que permite afirmar que sería la calle principal de la judería orensana-.

La «Rúa Nova» comenzaba en el muro que servía de defensa a la ciudad, -el sistema defensivo de la ciudad de Ourense, al carecer de muralla, estaba basado en el cierre de sus propias edificaciones, y en tramos discontinuos de cerca y de foso

\footnotetext{
${ }^{27}$ LACAVE, José Luis, Juderías y sinagogas españolas, Madrid 1992, 421-2.
} 
(carcava)-. Una de las puertas de la ciudad era la puerta de la Rúa Nova, protegida del exterior por un foso ${ }^{28}$, y terminaba en la «Praça do Canpo», actual Plaza Mayor, que era una de las plazas más importantes de la ciudad, dedicada principalmente al comercio, según se expresa en una ordenanza del obispo fray Pedro de Silva, quien la define, en el año 1448, como la: «mellor plaça que non outra nihuna que ouvese ena dita çidade» ${ }^{29}$.

En cuanto a su aspecto externo, sería una calle poco urbanizada y de tierra, al igual que el resto de las calles de la ciudad, pues las primeras noticias fiables de pavimentación en Ourense son del S. XVI, aunque en algunas zonas se hubiesen colocado piedras ${ }^{30}$. Era también una calle bastante despoblada, con terrenos libres $^{31}$ y espacios dedicados a huertas ${ }^{32}$.

Este modelo de dispersión de población judía por toda la ciudad se verá profundamente alterado después del 3 de julio de 1484 fecha en la que se ordenó, por primera vez, el apartamiento de los judíos a la judería.

\section{Del 3 de Julio de 1484 al 27 de Mayo de 1487}

La orden de separación de los judíos a barrios propios separados de los cristianos $\mathrm{y}$, sobre todo, de los conversos, fue una de las medidas adoptadas por los Reyes Católicos en las Cortes reunidas en Toledo en el año 1480.

Aunque en estas mismas Cortes se dio un plazo de dos años para hacer efectivo el apartamiento, en Ourense no se aplicaron estas leyes inmediatamente, sino que pasaron cuatro años hasta que, el 3 de Julio de 1484, se ordenó a ciertos judíos, cuyo nombre se cita expresamente, que en un plazo de tres días, y en cumplimiento de las Leyes de Toledo, se apartasen a vivir a una zona que les sería señalada: "querendo guardar la ley de Toledo, requeriron a Jacó Vello e a Samuel Albeytar e Ysaque Rodriga e a Ysaque Cabaleiro e a Jaco Cabaleiro judios, que doje en terçeyro dia se apartasen onde lles sería dado e asynado lugar $\rangle^{33}$.

Estos cinco judíos son los únicos judíos varones que se registran en el Padrón de la Santa Hermandad de 1484. Por lo tanto, la orden parece dirigida, exclusivamente, a aquellos judíos que eran vecinos de la ciudad.

${ }^{28}$ LÓPEZ CARREIRA, Anselmo, A cidade de Ourense no século XV, Ourense 1998, 57, nota 18.

${ }^{29}$ FERRO COUSELO, Xesús, $A$ vida e a fala dos devanceiros, Vigo 1996, tomo II, 142-44.

${ }^{30}$ LÓPEZ CARREIRA, Anselmo, A cidade de Ourense, 63.

${ }^{31}$ CASTRO, Manuel, y MARTÍNEZ SUEIRO, Manuel, Documentos del archivo Catedral de Orense, págs. 375-377

${ }^{32}$ Archivo Histórico Provincial de Ourense, Acordos III, 80.

${ }^{33}$ FERRO COUSELO, Xesús, $A$ vida e a fala, tomo II, 233. En el libro faltan nombres que están en el original y que se han añadido en este texto. 
La documentación no aclara cuál fue el resultado de esta orden ni si se fijó posteriormente la ubicación de la judería. Sin embargo, ha quedado constancia de que Jacob Vello no pudo cumplir la orden de apartamiento porque murió entre la fecha de la orden y el 15 de Agosto, fecha en que se terminó el padrón de la Santa Hermandad del año 1484 y en el cual cotiza "a moller que foy de Jaco Vello»" ${ }^{34}$. Isaac Rodriga y Jacob Cavaleiro no cumplieron la orden porque el 22 de Mayo de 1487 son requeridos de nuevo para que se aparten a vivir a la judería. Samuel Albeytar e Isaac Cabaleiro desaparecen de la documentación lo que puede ser indicativo, bien de que vivían en la judería, bien de que habían muerto, o bien de que se habían convertido al cristianismo.

El 22 de Mayo de $1487^{35}$, se observa un cambio radical en la actitud de los nuevos jueces de la ciudad. Estos no sólo señalaron la zona de la ciudad que se convertirá en judería, sino que hicieron una relación de todos aquellos judíos que debían trasladarse a ella y de las casas que habitarían cada uno de los trasladados. En algunos casos estas viviendas estaban ocupadas por cristianos que se negaban a abandonarlas y que reclamaron sus derechos ante los Reyes Católicos.

La judería, como zona exclusiva de los judíos, se situó en la «Rúa Nova». Este emplazamiento, como en la mayor parte de las ciudades, obedece a que era la calle donde ya habitaban mayoritariamente los judíos. Se estableció que se empezasen a ocupar primero las casas más pegadas al muro y se avanzase hacia la ciudad, de un lado y de otro de la calle: "començando junto da dita porta da vyla de hun cabo e do outro da calle, contra a çibdad». Es decir, se empieza asignando las casas más alejadas del centro comercial de la ciudad y, cabe suponer, las más baratas. Por otro lado, a los cristianos que vivían en las casas que han sido asignadas para los judíos, se les dio menos de una semana de plazo para que las abandonasen y se las cediesen bajo la amenaza de que si no lo hacían les serían aplicadas las penas contenidas en la ley.

Los judíos obligados a apartarse fueron los siguientes:

${ }^{34}$ LÓPEZ CARREIRA, Anselmo, Padróns de Ourense do século XV, Santiago de Compostela 1995, 131-42.

${ }^{35}$ FERRO COUSELO, Xesús.: A vida e a fala, tomo II, 235-37.

Cuadernos de Estudios Gallegos, Tomo LI, Fascículo 117, Santiago 2004. (Págs. 263 - 279) 


\begin{tabular}{ll}
\hline Judíos Trasladados & Propietario o morador de la casa asignada \\
\hline Isaac Rodriga, mercader & Gonçalo de Puga, regidor \\
\hline Judía Loytosa & Gomes de Peyn \\
\hline Juda Pérez, recaudador & María Casada \\
\hline $\begin{array}{l}\text { Abraán Abarca, platero, } \\
\text { Esposa: Rica de Samillan }\end{array}$ \\
\hline Mosé Pérez, recaudador \\
\hline $\begin{array}{l}\text { Samuel Ciano, platero, } \\
\text { Esposa: Ouro }\end{array}$ \\
\hline Jaco Cabaleiro & Alfonso Vázquez \\
\hline
\end{tabular}

\section{Después de 1487}

Sin embargo, y a pesar de todas las medidas adoptadas, la orden de 22 de Mayo de 1487 no fue del todo efectiva ya que no todos los judíos señalados abandonaron sus casas, lo que provocó una nueva intervención de los jueces quienes ordenaron, el 28 de Enero de $1488^{36}$, el traslado de: Abraán Abarca, platero, casado con Rica de Samillan; de Mosé Pérez, recaudador; de Samuel Ciano, platero, casado con Ouro; de Jaco Cabaleiro, de Don Ouro y de Alegría.

Excepto en dos casos, Isaac Rodriga y la judía Loytosa, -aunque Judá Pérez no es nombrado en la orden de 1488 presentará, junto a Mosé Pérez, un requerimiento, en una fecha posterior, explicando los motivos por los que no se apartó a la judería-, se nombra a los mismos judíos en los años 1487 y 1488 . A los hay que añadir, en este último año, dos personas más que son requeridas por primera vez: Ouro y Alegría. Esto es indicativo de que el apartamiento no se había completado.

Mención especial merece el caso de los recaudadores de la alcabala de Ourense y de su obispado, Judá Pérez y Mosé Pérez, a quienes se les había asignado en 1487 la casa de María Casada y de Aldara Gonçalves respectivamente, pero a la que no se trasladaron por lo que se les requirió de nuevo el 28 de Enero de 1488 y el 6 de Noviembre de 1488:

${ }^{36}$ FERRO COUSELO, Xesús, $A$ vida e a fala, tomo II, 235-37. 
«... outra vez lle mandauan ... se apartasen e se fuesen a beuir e morar a la judería ... e lles nonbrauan luego casa para el dicho Mose Peres, la casa de Gonçaluo de Puga, que está a la puerta de la villa, de la Rúa Noba, e pera el dicho Yudá Peres la casa del abad de Santo Estebo de Riba de Syl.... ${ }^{37}$.

Las casas de esta última orden no coinciden con las de la primera, pero no es posible, con la documentación actual, establecer cuáles fueron las causas de esta nueva asignación. Dentro del terreno de la suposición podemos pensar que, quizá, las casas que les habían sido asignadas inicialmente estuviesen ya ocupadas. Al requerimiento judicial respondieron, tanto Mosé como Judá, argumentando que no eran vecinos de Ourense: «que nos no somos vesinos desta dicha çibdad ni lo queremos ser ni tenemos en ella nuestras mujeres ni fyjos ni hasiendas ni queremos bybyr en ella ni estar residentes en ella"; que estaban de paso en su calidad de recaudadores de los reyes: "venimos a esta çibdad e avemos estado e estamos e estouiéremos en ella algunos dias, es para poner recabdo en las rentas de las alcabalas de la dicha çibdad e su obispado, que tenemos arrendadas del Rey e de la Reyna, nuestros senores»; y que, por lo tanto, el concejo tenía que proporcionarles un lugar seguro donde tener a buen recaudo las rentas de la alcabala, en tanto que las casas que les habían asignado no cumplían estas condiciones:

«... vosotros estades e sodes tenudos e obligados a nos dar posada en la dicha çibdad, sin dinero, sygund al thenor e forma de la ley del Quaderno, que no sean mesones, e para nos e para nuestros criados e fasedores, que nos sea tuta e sygura para tener en ella la fasienda de sus Altezas, que es a nuestro cargo ... Y por quanto las casas que nos nonbran son despobladas y en lugar donde no podríamos estar siguros nos ni nuestros fatores ni tener la fasienda de sus Altezas a buen recado en ellas, como dicho es ...».

Los conflictos derivados del traslado de los judíos de Ourense a la judería continuaron, al menos, hasta el año 1489, fecha en que se documenta la respuesta dada por los Reyes Católicos a los judíos de Ourense sobre el intento, por parte del concejo, de trasladar la judería a otra parte de la ciudad.

La zona elegida para la nueva judería fue la de la «Fuente del Obispo $»^{38}$. La puerta de la Fuente del Obispo es otra de las puertas de acceso a la ciudad de

\footnotetext{
${ }^{37}$ FERRO COUSELO, Xesús, $A$ vida e a fala, tomo II, 238-40.

${ }^{38}$ SUÁREZ FERNÁNDEZ, Luis, Documentos acerca de la expulsión de los judios, Valladolid 1964, 321-22.
}

Cuadernos de Estudios Gallegos, Tomo LI, Fascículo 117, Santiago 2004. (Págs. 263 - 279) 
Ourense, situada muy próxima a la puerta de la Rúa Nova. Tiene su origen en la puerta de la calle de los Arcedianos que, al crecer la ciudad, debió bajar a San Miguel o Fuente del Rey ${ }^{39}$. Quizá lo que esta orden pretendiese es que todas las casas de la judería corriesen pegadas al muro de la ciudad y no avanzasen hacia la Plaza Mayor.

Esta actitud de las autoridades orensanas motivó que los judíos de la ciudad se dirigieran a los Reyes Católicos pidiendo su intervención, que se produjo el 27 de Febrero de 1489 cuando se dirigieron a las autoridades de Ourense ordenándoles que dejasen la judería en el lugar que ocupó desde el primer momento: "mandandoles dexar al dicho sytyo en que asy fueron e estan apartados fasta aqui» ${ }^{40}$.

En este mismo documento queda constancia de la resistencia de algunos cristianos a abandonar sus casas y dejarlas libres para los judíos, y que habían sido requeridos judicialmente por las autoridades municipales:

«... apartaron los judios que en ella byben e les dieron sytios en la calle Nueva e requirieron a los christianos que en tales sytios bivian que les diesen sus casas para se pasar a ellas e algunos dellos e otros non quisieron salir de sus casa aunque fueron requeridos que las diesen a los dichos judíos ...».

Considerando que, aproximadamente en 1489 , había cristianos que no habían abandonado sus casas para dejárselas a los judíos, se puede suponer que, en consecuencia, también habría judíos viviendo fuera de la judería, por lo que es posible afirmar que la judería de Ourense tuvo una vida muy efímera, apenas tres años, que son los que median entre 1489 y 1492, fecha de la expulsión de los judíos de la península.

\section{Judería de A Coruña}

Sobre la ubicación del barrio judío de A Coruña han existido varias hipótesis: Una de ellas, basándose en la tradición, defiende el emplazamiento de la judería intramuros de la ciudad, en la actual calle Sinagoga; otra defiende su ubicación en la zona de «A Rabiada» o «Larrabiada», en el antiguo barrio de Santa Lucía; y, finalmente, otros autores defienden la coexistencia de ambos emplazamientos. Sin

\footnotetext{
${ }^{39}$ GALLEGO DOMÍNGUEZ, Olga, «Torres, puertas y cercas de la ciudad de Orense», Boletín Auriense, 11(1972), 271.

${ }^{40}$ SUÁREZ FERNÁNDEZ, Luis, Documentos acerca, 321-22.
} 
embargo, una carta de foro del año 1494, ha permitido situar la judería de A Coruña dentro de la Ciudad Vieja, muy próxima a la actual «Porta dos Ares»:

«... para que por nos e en nonbre del cabildo de la dicha yglesia posays partyr y faser partilla con Vasco Moro, notario, vecino de la dicha çibdad que esta presente, de una casa que es syta açerca de la porta dos Sares açerca de donde solia ser juderia que es en la colaçion de la dicha yglesia .... ${ }^{41}$.

El hecho de que este documento esté datado en el año 1494, es decir dos años después de la expulsión no permite conocer si los judíos habitaron dispersos por toda la ciudad y fueron apartados a esa zona después de 1480, como en el caso de Ourense, o si desde el principio vivieron agrupados en torno a una calle como en el caso de Ribadavia.

En cuanto a su aspecto externo, la judería de A Coruña sería, al igual que el de las otras zonas de la ciudad, el de una calle o conjunto de calles de tierra sin pavimentar, pues no fue hasta el año 1502, cuando tras una petición del concejo de $\mathrm{A}$ Coruña, el Consejo de Castilla solicitó al corregidor de A Coruña que informe sobre la conveniencia del pavimentado ${ }^{42}$.

\section{CONCLUSIONES}

Son varios los factores que influyeron en la formación de las juderías o barrios especiales de los judíos: la tendencia natural de toda minoría a aislarse para mantener su propia cultura, y la superioridad manifiesta de la sociedad cristiana que persiguió a través de todos los ámbitos legislativos la segregación social y espacial de las comunidades judías.

La existencia de juderías en Galicia se documenta fundamentalmente en el siglo $\mathrm{XV}$, aunque con anterioridad a esta fecha existan referencias a la judería de Allariz, lugar al que son apartados los judíos y donde también se prohibe entrar a los cristianos, como solución a los múltiples conflictos religiosos que en 1289, existen entre ambas comunidades. El resto de las juderías gallegas se ubicaron en Ribadavia, -en torno a la «calle de la judairía»-, en Ourense, - en torno a la «Rua

\footnotetext{
${ }^{41}$ BARRAL RIVADULLA, Dolores, «Nuevas aportaciones a la historia de la judería coruñesa, sus manifestaciones artísticas», Sefarad, 56 tomo II (1996), 434-35.

42 BARRAL RIVADULLA, Dolores, La Coruña en los siglos XIII al XV. Historia y configuración urbana de una villa de realengo en la Galicia medieval, A Coruña 1998, 96.
} 
Nova» fundamentalmente, lo que no impidió que habitaran también en otras calles de la ciudad- o en A Coruña - próxima a la «porta dos Ares»-. Esto no quiere decir que el resto de las comunidades judías documentadas en Galicia no tuvieran un barrio propio, sino que el concepto de «judería» no aparece en la documentación conservada sobre ellas y, por lo tanto, no han sido incluidas en este estudio. 